\title{
Immediate Outcome of Mechanically Ventilated Neonates: Experience from a Tertiary Care Hospital
}

\author{
Halder AL ${ }^{\mathrm{a}}$, Baki MA ${ }^{\mathrm{b}}$, Nahar Nc ${ }^{\mathrm{c}}$ Begum $\mathrm{T}^{\mathrm{d}}$
}

\begin{abstract}
Background: A large number of neonates in intensive care unit require mechanical ventilation due to various disease conditions. There has been a dramatic fall in neonatal mortality in developed countries with the advent of mechanical ventilation and the concept of neonatal intensive care. But still fatality rate is very high in developing countries. So, this study or was done to identify the immediate hospital outcome of the neonates who required mechanical ventilation.
\end{abstract}

Methods: This study was done in Special Care Baby Unit, BIRDEM General Hospital from July 2009 to June 2010. All neonates requiring mechanical ventilation during the study period were prospectively enrolled in this study. During the time of mechanical ventilation neonates were followed up to observe any complication till discharge or death.

Results: Total 37 neonates were enrolled in the study. Among them 27 (73\%) were preterm and 30 (81\%) were low birth weight. Respiratory distress syndrome was the most common reason for ventilation accounting for 17 (45.9\%) cases. The other indications were perinatal asphyxia (9, 24.3\%), congenital pneumonia (5, 13.5\%), septicemia $(5,13.5 \%)$ and meconium aspiration syndrome $(1,2.7 \%)$. The most common complication during the period of ventilation was septicemia $(14,37.8 \%)$. Other complication included pneumothorax $(6,16.2 \%)$, acute renal failure (5, 13.3\%), pneumonia (5, 13.3\%), pulmonary hemorrhage (3, 8.1\%), intraventricular hemorrhage (2, 5.4\%) and heart failure $(2,5.4 \%)$. The fatality rate was $38 \%$ and most of the infant died of perinatal asphyxia $(5,35.7 \%)$, septicemia $(4,28.5 \%)$, respiratory distress syndrome $(3,21.5 \%)$ and congenital pneumonia $(2,14.3 \%)$.

Conclusion: Respiratory distress syndrome was the most common reason for mechanical ventilation followed by perinatal asphyxia and septicemia. Most common complication during mechanical ventilation was septicemia which was also a common cause of death. Another important cause of death was perinatal asphyxia.

Key words: Mechanical ventilation; respiratory distress syndrome; perinatal asphyxia; neonatal sepsis.

Birdem Med J 2016; 6(1): 22-25

\section{Author Informations}

a. Dr. Amrita Lal Halder, FCPS (Paediatrics), Resident Physician, Department of Paediatrics, BIRDEM General Hospital, Dhaka.

b. Dr. Md Abdul Baki, MD (Neonatology), Assistant Professor, Department of Paediatrics, BIRDEM General Hospital, Dhaka.

c. Prof. Nazmun Nahar, FCPS (Paediatrics), FRCP (UK), Director General and Professor of Paediatrics, BIRDEM General Hospital, Dhaka.

d. Prof. Tahmina Begum, FCPS, MD (Paediatrics), MMEd, Professor of Paediatrics and Head, Department of Paediatrics, BIRDEM General Hospital, Dhaka.

Address of correspondence: Dr. Amrita Lal Halder, FCPS (Paediatrics), Resident Physician, Department of Paediatrics, BIRDEM General Hospital, Dhaka. Email: amritaantak@ gmail.com

Received: March 23, 2015

Accepted: November 30, 2015

\section{Introduction}

There has been a dramatic fall in neonatal mortality in developed countries with the advent of mechanical ventilation and the concept of neonatal intensive care. ${ }^{1}$ A large number of neonates in intensive care unit require mechanical ventilation due to respiratory distress syndrome (RDS), severe perinatal asphyxia (PNA), repeated apnea, meconium aspiration syndrome (MAS), pneumonia, sepsis, congenital heart disease and shock. ${ }^{2}$ Mechanical ventilation has definitely improved the survival of sick neonates but as a complex and invasive technology, mechanical ventilation can result in numerous complications such as pneumothorax, broncopulmonary dysplasia, pneumonia, nosocomial infection and intraventricular hemorrhage (IVH). ${ }^{2}$ These 
mechanically ventilated neonates also have a high fatality. ${ }^{3}$ Bangladesh is a resource poor country. The experience of neonatal ventilation in Bangladesh is not very advanced. In Bangladesh Institute of Research and Rehabilitation in Diabetes, Endocrine and Metabolic Disorders (BIRDEM) neonatal ventilation was started in 1995. This study was carried out to examine the outcome of neonates who required mechanical ventilation and to relate the outcome with diseases for which ventilation was initiated.

\section{Methods}

This study was done in Special Care Baby Unit (SCABU), BIRDEM General Hospital from July 2009 to June 2010. All neonates requiring mechanical ventilation during this period were prospectively included in this study. Babies who died within 6 hours of mechanical ventilation were excluded from the study. Babies with congenital anomalies were also excluded from this study. Machine used for mechanical ventilation is either infant Star or Bear cub infant ventilator (time cycled, pressure limited and continuous flow ventilator). The indications for mechanical ventilation were (i) $\mathrm{PaO}_{2}<50 \mathrm{~mm}$ of $\mathrm{Hg}$ or $\mathrm{SaO}_{2}<85 \%$ with $\mathrm{FiO}_{2}$ requirement more than 5 litre/min, (ii) $\mathrm{PaCO}_{2}>55 \mathrm{~mm}$ of $\mathrm{Hg}$ with $\mathrm{pH}<7.2$ or $\mathrm{PaCO}_{2}>60 \mathrm{~mm}$ of $\mathrm{Hg}$ and (iii) Intractable apneic spell. ${ }^{4}$ Temperature, pulse, respiration and oxygen saturation were continuously monitored in all neonates. Oxygen saturation was maintained between 90 and $95 \%$. Oxygen saturation was monitored by noninvasive pulse oximetry. Apnea monitor was used to monitor respiratory rate and heart rate. Arterial blood gas was monitored by Ciba-Corning 248 gas analyzer. Parameters of ventilator were recorded e.g. ventilation rates, peak inspiratory pressure, inspiratory time, peak end expiratory pressure, $\mathrm{FiO}_{2}$, gas flow. The ventilator settings were adjusted according to the underlying diseases and acid-base measurement. Weaning was attempted when the babies showed clinical improvement and blood gas report showed $\mathrm{PO}_{2} 60-90 \mathrm{mmHg}, \mathrm{PCO}_{2} 41-50 \mathrm{mmHg}, p^{\mathrm{H}}>7.30$ and when the baby had been stable. ${ }^{4}$ All data was recorded in a specially designed data collection sheet. After completion of data collection, the data was analyzed by using SPSS version 12.0 .

\section{Results}

Among the 37 neonates, there was male predominance $(30,70.3 \%)$ and male to female ratio was 3.6:1. About two third neonates $(26,70.3 \%)$ was out born. Mean gestational age was $32.59 \pm 3.54$ weeks. The mean birth weight of the study neonates was $1800 \pm 741 \mathrm{gm}$ of which $7(18.9 \%)$ was normal (>2500 gm) birth weight, 11 (29.7\%) were low birth weight $(<2500 \mathrm{gm}), 17(45.9 \%)$ were very low birth weight $(<1500 \mathrm{gm})$ and $2(05.4 \%)$ neonates were extreme low birth weight $(<1000 \mathrm{gm})$ babies.

RDS was the commonest indication (45.9\%) for mechanical ventilation. The other indications were PNA (24.3\%), congenital pneumonia (13.5\%), septicemia $(13.5 \%)$ and MAS (2.7\%). Most of the neonate developed complications while in the mechanical ventilator. Most common complication was septicemia (37.8\%) and other complications are presented in Table I. Among 37 ventilated neonates, 14 (38\%) died. Among them 05 (35.7\%) died of PNA, 4 (28.5\%) of septicemia, 3 (21.5\%) of RDS and $2(14.3 \%)$ died of congenital pneumonia. Survival rate was significantly more in neonates who required mechanical ventilation due to RDS and others are presented in Table II.

Table I. Complications occurred during ventilation $(\mathrm{N}=37)$

\begin{tabular}{lcc} 
Complication & Frequency & Percentage \\
\hline Sepsis & 14 & 37.8 \\
Pneumothorax & 6 & 16.2 \\
Acute renal failure & 5 & 13.3 \\
Pneumonia & 5 & 13.3 \\
Pulmonary haemorrhage & 3 & 8.1 \\
Intraventricular haemorrhage & 2 & 5.4 \\
Heart failure & 2 & 5.4 \\
\hline
\end{tabular}

More than one complication occurred in one or more cases

Table II. Outcome of mechanical ventilation in relation to indications

\begin{tabular}{lcccc} 
Indication & Death & Survivor & Chi-square & $p$ value \\
\hline RDS(17) & $3(17.6)$ & $14(82.4)$ & 3.9786 & 0.0123 \\
PNA(9) & $5(55.6)$ & $4(44.4)$ & 0.7479 & 0.1215 \\
Congenital & $2(40)$ & $3(60)$ & 0.1510 & 0.4535 \\
pneumonia (5) & & & & \\
Septicemia (5) & $4(80)$ & $1(20)$ & 2.5425 & 0.0310 \\
MAS (1) & $0(0)$ & $1(100)$ & 0.646 & 0.3108 \\
\hline
\end{tabular}




\section{Discussion}

In this study of neonates requiring mechanical ventilation there was a male predominance $(70.3 \%)$. The mean birth weight and gestational age of the ventilated neonates in this study were $1800 \pm 741$ gram and $32.59 \pm$ 3.54 weeks respectively. Seventy three percent (73\%) of the neonates were preterm. RDS was the major indication for mechanical ventilation (MV) in the present study comprising about $45.9 \%$ of the cases. It is also similar to other studies. ${ }^{3,5,6}$ Other indications for MV were perinatal asphyxia (24.3\%), septicemia (13.5\%) congenital pneumonia (13.5\%), and meconium aspiration syndrome (2.7\%). Munir MM studied 114 sick neonates among them $53(46.5 \%)$ required MV. The indications for MV were perinatal asphyxia, septicemia, RDS, congenital pneumonia, postoperative procedure and apnea of prematurity. ${ }^{7}$

In the present study, the most common complication developed during the period of mechanical ventilation was septicemia (37.8\%). It was simulated to Nangia S, et al. who found septicemia $(37.8 \%)$ as commonest complication. ${ }^{3}$ The pulmonary air leak was the common complication in western literature. ${ }^{8}$ In the present study, $6(16.2 \%)$ patient developed pulmonary air leak (pneumothorax). Other complications were acute renal failure (ARF) (13.3\%), pneumonia (13.3\%), pulmonary hemorrhage (8.1\%), IVH (5.4\%) and heart failure (5.4\%). All these complications were also commonly found in other studies. ${ }^{3,5,8}$ Fatality rate was high $(38 \%)$ in this study. In developed country it was $9-14 \% .{ }^{8}$ But in developing country it was $46-54 \% .{ }^{3,9,10}$ In a local study fatality rate was higher than our study and it was $75.5 \%{ }^{7}$

Differences in outcome of ventilated neonates between developed and developing countries may be related to the ready availability of surfactant and parenteral nutrition in developed countries as compared to developing countries. Limited manpower, technical expertise and technological advances in developing countries may also be an additional factor.

In our study, Only 3 (17.6\%) of 17 patients with RDS died and $82.4 \%$ survived. The difference was statistically significant $(\mathrm{p}<0.05)$. Infants with RDS need mechanical ventilation more but prognosis is good. Tortman $\mathrm{H}$ reported that babies who required mechanical ventilation due to RDS had $42 \%$ death in his study. ${ }^{5}$ This number is much more than current study. A large number of the babies in his study were extreme low birth weight.
Among 9 neonates who needed mechanical ventilation due to perinatal asphyxia, $5(55.6 \%)$ patients died which was almost similar to other studies. ${ }^{5,6}$ Five neonates were put on mechanical ventilation in this study due to septicemia and most of the neonate (80\%) died. Mortality was significantly more $(\mathrm{p}<0.05)$ in neonate needed mechanical ventilation due to septicemia. It is contrary to Maiya, et al. ${ }^{11}$ They found that all infants with sepsis requiring MV survived. In Lindroth's study, they showed that survival increased from 45 to $69 \%$ over the study period due to earlier diagnosis and treatment. ${ }^{12}$ Babies with MAS requiring MV had the best outcome in Tortman H's study, $82 \%$ survived. ${ }^{5}$ It is similar to our study. In our study one patient of RDS, we could give surfactant and the baby survived without any complication and with very short duration of mechanical ventilation. The value of surfactant in improving outcome of neonates with RDS, decreasing the length of ventilation and decreasing the incidence of some complications has been previously documented. ${ }^{13}$ Although, surfactant is available in our country but it is not accessible to the majority of patients because of high cost.

\section{Conclusion}

From this study it can be concluded that RDS is the most common reason for mechanical ventilation followed by perinatal asphyxia and septicemia. Outcome is good in neonate requiring mechanical ventilation due to RDS and bad in septicemia and perinatal asphyxia. Most common complications during mechanical ventilation were septicemia. The study population of the study was too small and it was done only in one specialized centre, so further study should be done in large scale to evaluate real outcome of mechanically ventilated neonates.

\section{Conflict of interest: None.}

\section{References}

1. Richardson DK, Gray JE, Gortmaker SL, Goldmann DA, Parsley DM, McCormick MC. Declining severity adjusted mortality: evidence of improving neonatal intensive care. Pediatrics 1998;102:893-99.

2. Truog WE. Complications of mechanical ventilation and airway control in the neonate. Respir Care 1986;31: 498-505.

3. Nangia S, Saili A, Dutta AK, Gaurvani MS, Seth A, Kumari S. Neonatal mechanical ventilation. Experience at a level II care centre. Indian J Pediatr 1998;65:291-96. 
4. Greenough A, Milner AD. Acute respiratory disease. In: Roberton NRC (ed). Textbook of Neonatology. $4^{\text {th }}$ edition. China; Elsevier Churchill Livingstone. 2005; p. 468-553.

5. Tortman H. The Neonatal Intensive Care Unit at the University Hospital of the West Indies: The first few years' experience. West Indian Med J 2006;55:75-79.

6. Mathur NC, Kumar S, Prasanna AL, Sahu UK, Kapoor R, Roy $\mathrm{S}$, et al. Intermittent positive pressure ventilation in a neonatal intensive care unit: Hyderabad experience. Indian Pediatr 1998;35:349-53.

7. Hossain MM, Shirin M, Mamun AM, Hassan AN, Shahidullah M. Predictors of Mortality in Ventilated Neonates in Intensive Care Unit. Bangladesh J Chield Health 2009;33 (3):78-79.

8. Singh M, Deorari AK, Paul VK, Mittal M, Shankar S, Munshi U, et al. Three year experience with neonatal ventilation from a tertiary care hospital in Delhi. Indian Pediatr 1993;30:783-89.
9. Riyas PK, Vijayakumar KM, Kulkarni ML. Neonatal mechanical ventilation. Indian J Pediatr 2003;70:53740 .

10. Kambarami R, Chidede O, Chirisa M. Neonatal intensive care in a developing country: outcome and factors associated with mortality. Cent Afr J Med 2000;46: 2057.

11. Maiya PP, Vishwanath D, Hegde S, Srinivas TP. Mechanical ventilation of newborn, experience from a level III NICU, Indian Pediatrics 1994;12:75-80.

12. Lindroth M, Svenningsen NW, Ahlstrom H, Johnson B. Evaluation of mechanical ventilation in newborn infants. Actra Padiatr Scand 1980;69:143-49.

13. Liechty EA, Donovan E, Purohit D, Gilhooly J, Feldman B, Noguchi A, et al. Reduction of neonatal mortality after multiple doses of bovine surfactant in low birth weight neonates with respiratory distress syndrome. Pediatrics 1991;88:19-28. 